\title{
Incidence and determinant of eclampsia and its associated complication in tertiary care hospital of Gujarat, India
}

\author{
Chirag Banker, Latika Mehta* \\ Department of Obstetrics and Gynecology, GMERS Medical College, Gandhinagar, Gujarat, India \\ Received: 18 October 2019 \\ Accepted: 19 November 2019 \\ *Correspondence: \\ Dr. Latika Mehta, \\ E-mail: drlatikamehta@gmail.com \\ Copyright: (c) the author(s), publisher and licensee Medip Academy. This is an open-access article distributed under \\ the terms of the Creative Commons Attribution Non-Commercial License, which permits unrestricted non-commercial \\ use, distribution, and reproduction in any medium, provided the original work is properly cited.
}

\begin{abstract}
Background: Eclampsia is one of common cause of maternal mortality in developing country like India. It can be detected and prevented if early ANC care is properly done. Mainstay of management in case of eclampsia is early delivery to improve the prognosis in terms of reducing maternal and perinatal morbidity and mortality.

Methods: This prospective study was carried out in the department of obstetrics and gynaecology, at tertiary care centre in the state of Gujarat, for a period of two years from July 2012 to June 2014. With purposive sampling method all patients admitted with complain of eclampsia is included in study. Details are taken in predesigned, pre-validated and prescribed proforma.

Results: Hospital based incidence of eclampsia in our study is $1.11 \%$. Majority of the patient were unbooked. Eclampsia is a disease of young primigravida, specifically teenage primigravida. Seventy-five percentage of eclampsia cases occurred in the antenatal period, $14 \%$ in intranatal period and $11 \%$ in the postnatal period.

Conclusions: In developing countries like India still eclampsia is major problem. Good antenatal care with increased antenatal visits may help in reducing the incidence. Increased incidence among young primigravida and low socioeconomic status group provides the target group for medical measures.
\end{abstract}

Keywords: Eclampsia, Preeclampsia, Pregnancy induce hypertension

\section{INTRODUCTION}

Globally hypertensive disorder of pregnancy contributes $14 \%$ of maternal death, it is approximately 42,000 mother per year. ${ }^{1,2}$ Nearly all of these deaths occur in lowresource settings $(99 \%){ }^{3}$ Hypertensive disorders of pregnancy (HDPs) affect about $10 \%$ of all pregnant women around the world and are an important cause of maternal and perinatal mortality and morbidity. Hypertensive disorders of pregnancy include chronic hypertension, gestational hypertension, pre-eclampsia and eclampsia. The majority of morbidity and mortality is associated with pre-eclampsia and eclampsia. Eclampsia is defined as new onset of grand mal seizure activity and or coma during pregnancy, labour or postpartum in a woman with signs or symptoms of preeclampsia. ${ }^{4,5}$ More than $50 \%$ occur in the third trimester. In more recent years, there has been an increasing shift in the incidence of eclampsia toward the postpartum period. This is presumably related to improved access to prenatal care, earlier detection of pre-eclampsia, and prophylactic use of magnesium sulfate.

It is one of the leading cause of maternal and perinatal mortality as well as morbidity throughout the world., ${ }^{6,7}$ Every year more than 50,000 maternal deaths occurred due to eclampsia, most of which occurs in developing countries. $^{8}$ Approximately 1 in 2000 deliveries are 
complicated by eclampsia in developed countries; whereas the incidence in developing countries is estimated around 1 in 100 to 1 in 1700 cases. $^{9}$

Mainstay of management in case of eclampsia is early delivery to improve the prognosis in terms of reducing maternal and perinatal morbidity and mortality. The current study was done to determine the incidence, clinical presentation and its determinants in patients of eclemsia who presented in tertiary care institute in Gujarat during the year July 2010-July 2012.

\section{METHODS}

This prospective study was carried out in the department of obstetrics and gynaecology, at tertiary care centre in Ahmedabad, Gujarat, for a period of two years from July 2012 to June 2014. The study setting is one of the largest tertiary care centre in the state of Gujarat with there are around fifteen admissions per day to the labour room. Administrative permissions were taken from hospital authority for the study. All the women admitted during pregnancy or within 42 days of termination of pregnancy or delivery who had complain of eclampsia and their complications were included in the study. Patients were informed about the purpose of the study and informed consents were taken from the patients who were ready to participate in the study.

\section{Inclusion criteria}

- Women admitted during pregnancy or within 42 days of termination of pregnancy or delivery who had complain of eclampsia or their complication

- Pregnant woman who were ready to give informed consents

- Pregnant woman who were able to give history during any stage of hospital admission.

\section{Exclusion criteria}

- Women admitted during pregnancy or within 42 days of termination of pregnancy or delivery who did not had complain of eclampsia or their complication

- Patients who were not ready to give informed consents

- Pregnant woman who were not able to give history during any stage of hospital admission.

All patients were treated as per the protocol. A detailed history with clinical symptoms and signs, laboratory investigations, management and neonatal outcome were recorded in the predesigned, pre-validated and prescribed proforma. On examination edema classified as: up to dorsum of foot as + , Up to knee joint as ++ , Thigh and ant. Abdominal wall as +++ and Generalised edema as ++++ . Amount of protein loss in urine classified as Trace if protein loss is $<0.1 \mathrm{gm} / \mathrm{lit}$, + if protein loss is $0.1-1 \mathrm{gm}$ / lit, ++ if protein loss is $1-5 \mathrm{gm} /$ lit, +++ if protein loss is $5-10 \mathrm{gm} /$ lit, ++++ if protein loss is $\geq 10 \mathrm{gm} / \mathrm{lit}$.

\section{Statistical analysis}

Data from proforma entered in Microsoft Excel and data analysis was done with the help of Epi info 7 software and categorical data were presented by percentage.

\section{RESULTS}

In this cohort of 10582 deliveries there were 118 cases of eclampsia over two years. This gives an incidence of eclampsia of $1.11 \%$, (11 per 1,000 deliveries). Out of these 118 patients 100 patients had given informed consent to take part in study. Majority of patients in this study were unbooked, out of 100 cases only 15 cases were registered. Majority of the patients (78\%) were from socioeconomically lower class. Seventy-five percentage of eclampsia cases occurred in the antenatal period, $14 \%$ in intranatal period and $11 \%$ in the postnatal period (Table 1).

Table 1: Demographic characteristics of eclampsia patients.

\begin{tabular}{|lll|}
\hline \multicolumn{2}{|l|}{ No. of cases } & Percentage \\
\hline Type of admission & \multicolumn{1}{l|}{} \\
\hline Emergency & 85 & $85 \%$ \\
\hline Registered & 15 & $15 \%$ \\
\hline Socioeconomical class & \\
\hline Middle & 22 & $22 \%$ \\
\hline Lower & 78 & $78 \%$ \\
\hline Systolic blood pressure & & \\
\hline$<150 \mathrm{mmHg}$ & 15 & $15 \%$ \\
\hline $150-160 \mathrm{mmHg}$ & 55 & $55 \%$ \\
\hline $160-170 \mathrm{mmHg}$ & 8 & $8 \%$ \\
\hline $170-180 \mathrm{mmHg}$ & 12 & $12 \%$ \\
\hline $180-190 \mathrm{mmHg}$ & 10 & $10 \%$ \\
\hline Diastolic blood pressure & \\
\hline$<100 \mathrm{mmHg}$ & 20 & $20 \%$ \\
\hline $100-110 \mathrm{mmHg}$ & 63 & $63 \%$ \\
\hline $110-120 \mathrm{mmHg}$ & 7 & $7 \%$ \\
\hline $120-130 \mathrm{mmHg}$ & 10 & $10 \%$ \\
\hline Type of eclampsia & & $75 \%$ \\
\hline Antepartum & 75 & $14 \%$ \\
\hline Intrapartum & 14 & $11 \%$ \\
\hline Postpartum & 11 & \\
\hline
\end{tabular}

The majority of eclampsia cases occurred in women aged $21-25$ years $(44 \% ; \mathrm{n}=44) ; 30 \%(\mathrm{n}=182)$ eclampsia occurred in women aged 20 years or below. Eclampsia is a disease of young primigravida, specifically teenage primigravida. More than half women (58\%) had convulsion after 32 weeks, suggesting more incidence near term pregnancy (Table 2 ).

Most of preeclampsia patients complain of edema and had proteinuria on testing. In present study, only $7 \%$ patients had no edema $69 \%$ patients had ++ or higher grade edema. Five percent patients did not had proteinuria on admission and 63 had massive proteinuria. 
In this study $75 \%$ of patients were conscious but irritable; level of consciousness indicates poor prognosis with increasing grades. In the present series of study, 35 patients had headache, which are generally over the frontal and occasionally occipital occurs due to high blood pressure and did not respond to analgesics (Table 3).

Table 2: Determinants of eclampsia in patients at hospital.

\begin{tabular}{|lcc|}
\hline \multicolumn{2}{|c|}{ No. of cases } & Percentage \\
\hline Age of patients & \\
\hline $18-20$ & 30 & $30 \%$ \\
\hline $21-25$ & 44 & $44 \%$ \\
\hline $26-30$ & 19 & $19 \%$ \\
\hline$>30$ & 7 & $7 \%$ \\
\hline Parity of patients & \\
\hline Nulliparous & 68 & $68 \%$ \\
\hline 1 & 19 & $19 \%$ \\
\hline 2 & 6 & $6 \%$ \\
\hline 3 & 2 & $2 \%$ \\
\hline 4 & 3 & $3 \%$ \\
\hline 5 & 2 & $2 \%$ \\
\hline Previous history of hypertensive disorder \\
\hline P/H of PIH & 9 & $9 \%$ \\
\hline P/H of Eclampsia & 2 & $2 \%$ \\
\hline Gestational age in eclampsia patients \\
\hline$<28$ weeks & 5 & $5 \%$ \\
\hline $28-32$ weeks & 37 & $37 \%$ \\
\hline 33 to 36 weeks & 58 & $58 \%$ \\
\hline
\end{tabular}

Table 3: Clinical presentation of eclampsia patients at hospital.

\begin{tabular}{|lll|}
\hline \multicolumn{2}{l}{ No. of cases } & Percentage \\
\hline Degree of oedema & & \\
\hline No oedema & 7 & $7 \%$ \\
\hline+ & 24 & $24 \%$ \\
\hline++ & 52 & $52 \%$ \\
\hline+++ & 15 & $15 \%$ \\
\hline++++ & 2 & $2 \%$ \\
\hline Degree of proteinuria & & \\
\hline No proteinuria & 5 & $5 \%$ \\
\hline Trace & 8 & $8 \%$ \\
\hline+ & 4 & $4 \%$ \\
\hline++ & 20 & $20 \%$ \\
\hline+++ & 32 & $32 \%$ \\
\hline++++ & 31 & $31 \%$ \\
\hline Mental status of patients & \\
\hline Conscious & 75 & $75 \%$ \\
\hline Drowsiness & 15 & $15 \%$ \\
\hline Stupor & 8 & $8 \%$ \\
\hline Coma & 2 & $2 \%$ \\
\hline Symptoms during aura & & \\
\hline Headache & 35 & $75 \%$ \\
\hline Vomiting & 7 & $11 \%$ \\
\hline Blurring of vision & 11 & $6 \%$ \\
\hline Epigastric pain & 6 & \\
\hline & & \\
\hline
\end{tabular}

\section{DISCUSSION}

In this hospital-based study, incidence of eclampsia is $1.11 \%$. This finding is comparable with study by Olakunle et al (1.66\%). ${ }^{10}$ One multicentric communitybased study at south east region show the lower $(0.5 \%)$ incidence rate compare to this study. ${ }^{11}$ It is hospital-based study it caters high percentage of referred cases giving higher incidence of eclampsia. Incidence of eclampsia was more common in unbooked cases in this study. These results are agreement with other studies. ${ }^{10,12,13}$ Regular, frequent and efficient antenatal visits are important for prevention of eclampsia. By efficient antenatal care preeclampsia can be detected earlier and eclampsia can be minimized. This study shows the higher incidence in socioeconomically lower class. This can be explained by lack of antenatal visits by these women. In this study $75 \%$ of eclampsia cases occurred in the antenatal period and $11 \%$ in the postnatal period. The proportion of eclampsia cases occurring in the antenatal period was slightly higher than the other Indian study. ${ }^{14}$

Eclampsia is a disease of young primigravida, specifically teenage primigravida. In this study, nearly a third of eclampsia cases occurred in women aged under 20 years. Other studies have reported rates of $26 \%$ to $55 \% .^{15,16}$ The incidence below the age group 20 years is 4.9 times higher than the age group more than 20 years. ${ }^{16}$ Here the slight shift from teenage to 21-25 years can be explained by late marriages in last few years. Existing literature suggests that teenage pregnant women are at greater risk of eclampsia and their care should be prioritized in clinical practice. ${ }^{17}$ Interventions aiming to overcome the complex socio-cultural needs of this group to improve access to healthcare and prevent eclampsia warrant further research.

\section{CONCLUSION}

In this study around ten percentage of patients had past history of PIH or eclampsia. In this study more than half patients had eclampsia after 32 weeks of gestation. Highest incidence of eclampsia occurs between 28-37 weeks requires some screening test. GANT suggested that angiotensin II sensitivity test is to be done in between 28-32 weeks of pregnancy in all nulliparous and high-risk multiparous patients. Roll over test is the simplest screening test be the prediction of PIH. This test also be done between 28-32 weeks of pregnancy. Early detection and proper management of PIH/preeclampsia reduces the incidence of eclampsia.

\section{ACKNOWLEDGMENTS}

Authors would like to thank the patients and their relatives for supporting the study.

Funding: No funding sources

Conflict of interest: None declared 
Ethical approval: The study was approved by the Institutional Ethics Committee

\section{REFERENCES}

1. World Health Organization. Trends in maternal mortality: 1990 to 2015. Estimates by WHO, UNICEF, UNFPA, The World Bank and the United Nations Population Division. Geneva: World Health Organization; 2015. Available at: http://apps.who.int/iris/bitstream/10665/194254/1/ 9789241565141_eng.pdf?ua=1.

2. Say L, Chou D, Gemmill A, Tuncalp O*, Moller AB, Daniels J, et al. Global causes of maternal death: a WHO systematic analysis. Lancet Glob Health. 2014;2(6):e323-33.

3. Knight $M$, Nair M, Tuffnell D, Kenyon S, Shakespeare J, Brocklehurst P, et al. editors. Saving lives, improving mothers' care-surveillance of maternal deaths in the UK 2012-14 and lessons learned to inform maternity care from the UK and Ireland Confidential Enquiries into Maternal Deaths and Morbidity 2009-14. Oxford: Nuffield Department of Population Health; 2016.

4. Sibai BM. Diagnosis, prevention and management of eclampsia. Obst Gynesol. 2005;105(2):402-10.

5. Matter F, Sibai BM. Eclampsia VIII. Risk factor for maternal morbidity, AM J Obstet Gynecol. 1990;163:1049-55.

6. Dare FO, Eniola OA, Bariweni AC. Eclampsia revisited. Nig J Med. 1998;7:168-71.

7. Adetoro OD. The pattern of eclampsia at the university of Ilorin Teaching Hospital. Ilorin Nigeria, Int J Gynol Obstet. 1990;31:221-6.

8. Duley L. Maternal Morality associated with hypertensive disorders of pregnancy in Africa, Asia, Latin America and Caribbean. Br J Obstet Gynecol. 1992;99(7):547-53.

9. Duley L Preeclampsia and the hypertensive disorders of pregnancy. Br Med J. 2003;67:161-76.

10. Akinola O, Fabamwo A, Gbadegesin A, Ottun A, Kusemiju O. Improving the clinical outcome in cases of eclampsia: the experience at Lagos State University Teaching Hospital, Ikeja. The Int J Third World Med. 2007;6:2.

11. Vousden N, Lawley E, Seed PT, Gidiri MF, Goudar $\mathrm{S}$, Sandall J, et al. Incidence of eclampsia and related complications across 10 low- and middle-resource geographical regions: Secondary analysis of a cluster randomized controlled trial. PLoS Med. 2019;16(3):e1002775.

12. Tukur J, Umar BA, Rabi RU. Pattern of eclampsia in a tertiary health facility situated in a semi-rural town in Northern Nigeria. Ann Afr Med. 2007:6(4):164-7.

13. Chekairi MM, A eclampsia, study of 342 cases. Hypert Preg. 2008;27(2):103-11.

14. Majhi A, Chakraborthy P, Mukhopadhyaya A, Eclampia: present scenerio in a referral medical college, Calcutta. J Obstet Gynecol India. 2000;50:128-32.

15. Abalos E, Cuesta C, Carroli G, Qureshi Z, Widmer M, Vogel JP, et al. Pre-eclampsia, eclampsia and adverse maternal and perinatal outcomes: a secondary analysis of the World Health Organization multicountry survey on maternal and newborn health. BJOG. 2014;121(Suppl 1):14-24.

16. Vigil-De Gracia P, Rojas-Suarez J, Ramos E, Reyes $\mathrm{O}$, Collantes J, Quintero A, et al. Incidence of eclampsia with HELLP syndrome and associated mortality in Latin America. Int $\mathbf{J}$ Gynaecol Obstet. 2015;129(3):219-22.

17. Ganchimeg T, Ota E, Morisaki N, Laopaiboon M, Lumbiganon $\mathrm{P}$, Zhang $\mathrm{J}$, et al. Pregnancy and childbirth outcomes among adolescent mothers: a World Health Organization multicountry study. BJOG. 2014;121(Suppl 1):40-8.

Cite this article as: Banker $\mathrm{C}$, Mehta L. Incidence and determinant of eclampsia and its associated complication in tertiary care hospital of Gujarat, India. Int J Reprod Contracept Obstet Gynecol 2020;9:221-4. 